\title{
Decrease in the Hospital Stay of Neonates with Suspected Nosocomial Sepsis with the Use of a Molecular Biology Technique
}

\author{
Jesús Reyna-Figueroa1*, María Fernanda Rodríguez-Sánchez1, \\ Pilar Miyoko Martínez Matsumotoํㅜ, Federico Javier Ortiz-Ibarra², Ana Elena Limón-Rojas ${ }^{1}$ \\ ${ }^{1}$ Hospital Central Sur de Alta Especialidad, Petróleos Mexicanos, Mexico City, Mexico \\ ${ }^{2}$ Hospital Ángeles del Pedregal, Mexico City, Mexico \\ Email: *jesusreynaf@gmail.com
}

How to cite this paper: Reyna-Figueroa, J., Rodríguez-Sánchez, M.F., Matsumoto, P.M.M., Ortiz-Ibarra, F.J. and Limón-Rojas, A.E. (2019) Decrease in the Hospital Stay of Neonates with Suspected Nosocomial Sepsis with the Use of a Molecular Biology Technique. Journal of Biosciences and Medicines, 7, 44-51.

https://doi.org/10.4236/jbm.2019.73005

Received: January 26, 2019

Accepted: March 3, 2019

Published: March 6, 2019

Copyright ( 2019 by author(s) and Scientific Research Publishing Inc. This work is licensed under the Creative Commons Attribution International License (CC BY 4.0).

http://creativecommons.org/licenses/by/4.0/

(c) (i) Open Access

\begin{abstract}
Introduction: Diagnostic alternatives that allow microbial identification in blood, such as molecular biology; have shown utility in neonatal sepsis. Objective: To evaluate the impact of a Light Cycler SeptiFast test (LCSF) on days of hospital stay and the use of newborn (NB) antibiotics with suspected sepsis. Methods: We included NB with LCSF test and blood culture (cases) and NB with only blood culture (controls). We evaluated the days of stay, days of antimicrobial use and number of deaths. Statistic analysis: Descriptive statistics was used. The association between the use of LCSF and variables such as mortality, days of stay, use of antimicrobials, and use of mechanical ventilation was analyzed by odds ratio with $95 \%$ CI. Results: We included 20 subjects in the case group and 40 in the control group. 8 (40\%) of the cases were positive vs $6(15 \%)$ of the controls in the control group. In the controls, the average days of stay were $65+15$ vs $35+10$ days of the cases $(p<0.05)$. There was no significant difference in mortality, nor in antimicrobial use. The use of molecular biology was a protective factor for prolonged stay OR 0.2 (95\% CI $0.08-0.5) p=0.001$. Conclusions: The LCSF test influences the days of hospital stay, but does not impact mortality or the use of antimicrobials.
\end{abstract}

\section{Keywords}

Sepsis, Newborns, Inpatient Stay, SeptiFast

\section{Introduction}

The indicators measure the use of the bed resource, such as days of hospital stay, 
together with indicators of aggregate data (continuous or based on rates) such as in-hospital mortality; they are constantly reviewed by health systems around the world, to evaluate the quality of their services [1] in diseases such as nosocomial sepsis, considered one of the main causes of death in Newborns (NB); the problem for its diagnosis also favors the indiscriminate use of antibiotics and antimicrobial resistance, to the increase in the days of hospitalization and consequently increases the costs generated by the disease [2].

In recent years, the diagnostic alternatives that allow microbial identification in blood, such as molecular biology; have shown, in comparison with blood culture, and greater efficacy in the detection of the different pathogenic species that cause sepsis, which is a benefit for the NB [3] [4] and an impact on the health indicators, considering that if the antimicrobial therapy is properly administered in the septic patient, it will improve the survival, and the days of stay and decrease the costs in antibiotics [5] [6]. Contradictorily, even with the favorable results presented in different studies, molecular biology techniques have not been able to position themselves as the diagnostic standard of sepsis in daily clinical practice [7] [8].

We previously published a cohort in which we compared the diagnostic efficacy of Light Cycler SeptiFast ${ }^{\circledR}$ Roche (LCSF) compared to blood culture; finding a sensitivity of 0.69 and specificity of 0.65 , with a concordance for the detection of microorganisms of 0.21 (Kappa value); LCSF detected a greater number of microorganisms than blood culture [9], pending the evaluation of the impact of the use of the commercial technique of molecular biology on days of hospital stay, the use of antibiotics and the mortality of newborns with suspected sepsis.

\section{Material and Methods}

\subsection{Population}

Through a case-control study, we included NB patients with suspected sepsis from the pediatric service of the South Central Hospital of High Specialty of Petróleos Mexicanos (Mexico), attended from 2014 to 2016; to those who were asked for the LCSF test and blood culture (considered cases) and to NB with suspicion of sepsis to which only the blood culture was requested (called controls).

\subsection{Operational Definitions}

1) Suspicion of sepsis: Considered for the inclusion of subjects, the NB who met a score $>8$ according to the criteria of NOSEP-1, previously validated in the Mexican population, which includes a C-reactive protein greater than $14 \mathrm{mg} / \mathrm{L}$, total parenteral nutrition use $>14$ days, total platelet count $<150,000 / \mathrm{mm}^{3}$, temperature $>38.2^{\circ} \mathrm{C}$, total neutrophils $>50 \%$ [10] [11].

2) Sepsis: Sepsis was considered in the NB who, in addition to clinical data, identified one or more microorganisms in a blood sample, by blood culture (positivity before 48 hours) according to Yale criteria [12], to rule out contamina- 
tion, positivity in LCSF or in both.

We also evaluated the clinical, laboratory, stay days, days of antimicrobial use and number of deaths. The data was obtained from the institutional electronic clinical record and the laboratory records of the hospital, through paired review by two of the researchers, to validate the information obtained. As well as the database obtained from the previous multicentre study and from which the cases corresponding to the institution were selected.

\section{Statistic Analysis}

The demographic characteristics were analyzed using descriptive statistics, mainly averages and medians. The association between the use of LCSF and variables such as mortality, days of stay, use of antimicrobials, and use of mechanical ventilation was analyzed by odds ratio with $95 \%$ CI. Sampling was done for convenience.

\section{Ethics}

The study was approved by the research committee and the research ethics committee of the Central Sur Hospital of Petróleos Mexicanos with registration number $16 / 14$. For the type of study it was considered not to request informed consent.

\section{Results}

We include 60 samples; 20 in the group of cases and 40 in the group of controls with a ratio of 1:2; that will reduce some experimental errors.

The population was similar in its general characteristics, having 7 and $16 \mathrm{fe}-$ male patients in each group respectively; finding that the weight was similar in both groups; 1.098 vs $1.060 \mathrm{~g}$ respectively; with respect to the weeks of gestation, $20 \%$ were greater than 37 weeks in the cases vs $25 \%$ in the control group ( $p=$ $0.1)$.

It was observed that the positivity of the molecular biology test in $8(40 \%)$ of the cases, compared to 6 (15\%) of the blood cultures of the control group. Two samples with polymicrobial isolation result were presented in the cases vs zero polymicrobial isolations in the controls (Table 1).

Regarding the days of hospitalization, there was a significant difference between both groups, since in the controls the average days of stay was $65+15$ days in hospitalization, compared to the cases with $35+10$ days $(\mathrm{p}<0.05)$.

\section{Mortality}

The mortality data are presented in Table 2. We observed that the mortality among the NB in whom LCSF was used compared to those who only requested blood culture, the percentage of $10 \%$ vs $12.5 \%$ respectively, $\mathrm{p}=0.07$.

For the days of antimicrobial use, the need and days of mechanical ventilation, no significant difference was observed between the groups. The use of molecular 
biology was a protective factor for prolonged stay OR $0.2(95 \%$ CI $0.08-0.5) \mathrm{p}=$ 0.001; while for death and prolonged ventilation it was not significant (see Table $3)$.

Table 1. Microbiological results of newborns included in the study.

\begin{tabular}{ccc}
\hline Isolations & $\begin{array}{c}\text { Septifast results/Blood } \\
\text { culturen }=20(\%)\end{array}$ & $\begin{array}{c}\text { Blood culture results } \\
\mathrm{n}=40(\%)\end{array}$ \\
\hline Escherichiacoli & $2(10) / 2(10)$ & $1(2.5)$ \\
Staphylococcusepidermidis & $1(5) / 1(5)$ & $2(5)$ \\
Klebsiellapneumoniae & $1(5) / 1(5)$ & $1(2.5)$ \\
Candidaalbicans & $2(10) / 0$ & $1(2.5)$ \\
Staphylococcuscoagulasa negativa + \\
Klebsiellapneumoniae + \\
Enterobactercloacae
\end{tabular}

Table 2. Demographic data of the population.

\begin{tabular}{cccc}
\hline Variable & Cases $\mathrm{n}=20$ & Controls $\mathrm{n}=40$ & $\mathrm{p}$ \\
\hline Age; media & $12 \pm 7$ & $13 \pm 10$ & 0.06 \\
Female (\%) & $7(35)$ & $16(40)$ & 0.1 \\
Weightg (media) & $1.098 \pm 250$ & $1.060 \pm 270$ & 0.07 \\
Nosep-1 (average score) & $18 \pm 4$ & $17 \pm 5$ & 0.5 \\
Mortality (\%) & $2(10)$ & $5(12.5)$ & 0.07 \\
Hospital stay & $35 \pm 10$ & $65 \pm 10$ & 0.03 \\
Antimicrobial days & $17(7-24)$ & $24(14-25)$ & 0.07 \\
Need for ventilation & $80 \%$ & $75 \%$ & 0.06 \\
Days of ventilation & $11(5-14)$ & $12(8-16)$ & 0.07 \\
\hline
\end{tabular}

Table 3. Association of the use of molecular biology with outcome variables.

\begin{tabular}{cccc}
\hline Variable & Odds ratio & Interval (95\% IC) & $\mathrm{p}$ \\
\hline Extended stay & 0.2 & $0.08-0.5$ & 0.001 \\
Death & 0.5 & $0.1-1.4$ & 0.1 \\
$\begin{array}{c}\text { Prolonged use } \\
\text { of antibiotics }\end{array}$ & 0.3 & $0.1-2.0$ & 0.07 \\
$\begin{array}{c}\text { Prolonged use of } \\
\text { mechanical ventilation }\end{array}$ & 0.7 & $0.5-1.2$ & 0.1 \\
\hline
\end{tabular}




\section{Discussion}

The understanding of neonatal sepsis as a disease with a critical impact on public health is based on the identification of factors that magnify the problem favoring prolonged hospital stays and increasing the use of resources in treatment [13]. The high degree of variation in the clinical judgment adds to the difficulty of microbial identification, being key reasons for overdiagnosis and the indiscriminate use of antimicrobials [14].

Neonatal sepsis is a difficult disease to diagnose, due to the extensive list of known clinical manifestations and the myriad of proposed tests that do not identify it in a timely manner [15]. Consequently, rapid diagnostic tests capable of detecting infections in newborns have the potential to significantly impact neonatal care [16], under the argument that the detection of microbial DNA in the blood in a few hours facilitates timely treatment and this can influence the care of patients with sepsis, by decreasing, among others, the use of antimicrobials, mortality and hospital stay [17] [18], however, there are few studies that address the impact on these indicators, especially in newborn. The data found in our study establish that the use of LCSF impacts on hospital stay significantly, but does not influence the use of antimicrobials, mortality, or the need for mechanical ventilation, these results are similar to those found in other studies. performed in adults; as an example, Álvarez J et al. found a significant difference ( $p<0.05$ ) in the length of hospital stay (18.3 vs 21.3 days) of the group in which LCSF and the control group were used, respectively, referring to the main finding of this study shortening the stay in the intensive care unit [18]; Markota et al. observed that there is no difference in the cost of antimicrobial treatment when comparing subjects with positive LCSF vs negative results [19].

Previously it has been demonstrated in case reports that the use of LCSF has been useful in the improvement of complicated patients, with prolonged stays and with the use of broad spectrum antibiotics; in 2010, in a 33-year-old woman with a diagnosis of septic shock of abdominal origin, Candida krusei was identified, presenting improvement to the use of specific antifungal agents [20]. In 2011 LCSF was used simultaneously in two patients with systemic inflammatory response syndrome and negative cultures in whom broad spectrum antibiotics were administered without visible improvement. The first case was a 17-month patient with a diagnosis of septic shock of abdominal origin, with negative cultures on three occasions; the molecular biology test with a blood sample from the permanent catheter was requested as an alternative and genetic material of Candida parapsilosis and Klebsiella pneumoniael oxytoca was identified, reason for which the catheter was removed, with an adequate response from the patient who withdrew from the catheter, resolve the infection. The second case corresponded to a male of 16 days of life who was admitted from birth in the service of infants due to respiratory distress and necrotizing enterocolitis; at 72 hours of the suspension of the antimicrobial treatment started with fever, abdominal distension, leukopenia and thrombocytopenia. New cultures and the LCSF test with 
one milliliter of peripheral blood were requested, which identified Candida parapsilosis as the causative agent. The treatment was changed to amphotericin $\mathrm{B}$ deoxycholate with improvement 24 hours after the change. Indirectly, the early and simultaneous identification of Candida parapsilosis in two patients by molecular biology methods triggered the epidemiological alert that prevented its dissemination to other patients; the late result of the positive culture in one case and the negative result of the other would not have allowed taking action in a timely manner [21].

The main consequence of the variability exemplified above is that the abuse of antibiotics occurs as a consequence of seeking to prevent mortality due to sepsis [22]; which reinforces the concept known historically, that the decision to administer or not antimicrobial, depends more on the clinical evolution and the identified picture, than on the result of the different biomarkers or diagnostic tools proposed for sepsis [23] [24].

Some limitations of the present study should be taken into account. In the first place, being a retrospective study, we did not examine the possibility of contamination during the identification process, a factor that impacts the efficacy of most trials according to previous studies [25], however, the conditions for inclusion in the study prior guarantee that none of the isolates would be considered contaminated. Coagulase-negative staphylococci were considered sepsis agents in these children because these bacteria are frequently isolated in the Mexican population and all presented clinical signs of sepsis [2]. Due to the characteristics of the study, we did not perform a cost analysis.

\section{Conclusion}

The LCSF test influences the days of hospital stay, but does not impact mortality or the use of antimicrobials. Studies are needed to establish the economic impact of the use of this tool.

\section{Conflicts of Interest}

The authors declare no conflicts of interest regarding the publication of this paper.

\section{References}

[1] Jiménez, P.R. (2004) Indicadores de calidad y eficiencia de los servicios hospitalarios. Una mirada actual. Rev Cubana Salud Pública, 30, 27-32.

[2] Reyna, F.J., Ortiz, I.F.J., Esteves, J.A. and Reyna, F.J. (2009) Costo económico marginal del fracaso terapéutico con ampicilina más amikacina en el tratamiento de la sepsis neonatal temprana [Cost of Therapeutic Failure of Ampicillin plus Amikacin in the Treatment of Early Neonatal Sepsis]. Anales de Pediatría, 71, 54-59. https://doi.org/10.1016/j.anpedi.2009.03.013

[3] Torres, E., Pérez, M., Pedrosa, I., Peña, M., Jiménez, M. and Pérez, M. (2013) Evaluación de la técnica LightCycler ${ }^{\circledR}$ SeptiFast en recién nacidos y lactantes con sospecha de sepsis [Evaluation of the LightCycler ${ }^{\circledast}$ SeptiFast Test in Newborns and 
Infants with Clinical Suspicion of Sepsis]. Enfermedades Infecciosas y Microbiología Clínica, 31, 375-379. https://doi.org/10.1016/j.eimc.2012.09.012

[4] Troger, B., Hartel, C., Buer, J., Dordelmann, M., Felderhoff-Muser, U., Hohn, T., et al. (2016) Clinical Relevance of Pathogens Detected by Multiplex PCR in Blood of Very Low Birth Weight Infants with Suspected Sepsis-Multicentre Study of the German Neonatal Network. PLoS ONE, 11, e0159821.

https://doi.org/10.1371/journal.pone.0159821

[5] Korber, F., Zeller, I., Grünstäudl, M., Willinger, B., Apfalter, P., Hirschl, A. and Makristathis, A. (2017) SeptiFast versus Blood Culture in Clinical Routine-A Report on 3 Years' Experience. Wiener Klinische Wochenschrift, 129, 427-434. https://doi.org/10.1007/s00508-017-1181-3

[6] Straub, J., Paula, H., Mayr, M., Kasper, D., Assadian, O., Berger, A., et al. (2017) Diagnostic Accuracy of the ROCHE SeptiFast PCR System for the Rapid Detection of Blood Pathogens in Neonatal Sepsis-A Prospective Clinical Trial. PLoS ONE, 12, e0187688. https://doi.org/10.1371/journal.pone.0187688

[7] Gies, F., Tschiedel, E., Felderhoff-Müser, U., Rath, P.M., Steinmann, J. and Dohna-Schwake, C. (2016) Prospective Evaluation of SeptiFast Multiplex PCR in Children with Systemic Inflammatory Response Syndrome under Antibiotic Treatment. BMC Infectious Diseases, 16, 378. https://doi.org/10.1186/s12879-016-1722-9

[8] Kasper, D.C., Altiok, I., Mechtler, T.P., Bohm, J., Straub, J., Langgarrtner, M., Pollak, A., Herkner, K.R. and Berger, A. (2013) Molecular Detection of Late-Onset Neonatal Sepsis in Premature Infants Using Small Blood Volumes: Proof-of-Concept. Neonatology, 103, 268-273. https://doi.org/10.1159/000346365

[9] Ortiz, I.F.J., Treviño, V.P., Valenzuela, M.E., Limon, R.A.E., Lara, F.G., Ceballos, B.A., Morales, M.I., Fernandez, C.L., Covian, M.E. and Reyna, F.J. (2015) Evaluation of the Ligth-Cycler SeptiFast Test in Newborns with Suspicion of Nosocomial Sepsis. Iranian Journal of Pediatrics, 25, e253.

[10] Reyna, F.J., Briseño, V.R. and Ortiz, I.F.J. (2005) Validación de la escala NOSEP-1 para el diagnóstico de sepsis nosocomial en recién nacidos prematuros menores de $1500 \mathrm{~g}$ [Diagnosis of Nosocomial Sepsis in Neonates under $1500 \mathrm{~g}$ by Means of NOSEP-I Score]. Boletín médico del Hospital Infantil de México, 62, 321-28.

[11] Mahieu, M.L., de Muynck, O.A., de Dooy, J.J., Laroche, M.S. and Van Acker, J.K. (2000) Prediction of Nosocomial Sepsis in Neonates by Means of a Computer-Weighted Bedside Scoring System (NOSEP Score). Critical Care Medicine, 28, 2026-2033. https://doi.org/10.1097/00003246-200006000-00058

[12] Klein, O.J. (2001) Bacterial Sepsis and Meningitis. In: Remington, J.S. and Klein, J.O., Eds., Infectious Diseases of the Fetus and Newborn Infant, 5th Edition, WB Saunders, Philadelphia, 550-553.

[13] Angus, D.C., Linde-Zwirble, W.T., Lidicker, J., Clermont, G., Carcillo, J. and Pinsky, M.R. (2001) Epidemiology of Severe Sepsis in the United States: Analysis of Incidence, Outcome, and Associated Costs of Care. Critical Care Medicine, 29, 1303-1310. https://doi.org/10.1097/00003246-200107000-00002

[14] Gonzalez, G.L. (2009) Severe Sepsis and Septic Shock in Children: Not All Has Been Said. Revista Panamericana de Salud Pública, 26, 562-564.

https://doi.org/10.1590/S1020-49892009001200014

[15] Shane, A.L., Sánchez, P.J. and Stoll, BJ. (2017) Neonatal Sepsis. The Lancet, 390, 1770-1780. https://doi.org/10.1016/S0140-6736(17)31002-4

[16] Mussap, M., Molinari, M.P., Senno, E., Gritti, P., Soro, B., Mannelli, S. and Fabris, C. (2007) New Diagnostic Tools for Neonatal Sepsis: The Role of a Real-Time Po- 
lymerase Chain Reaction for the Early Detection and Identification of Bacterial and Fungal Species in Blood Samples. Journal of Chemotherapy, No. 2, 31-34. https://doi.org/10.1080/1120009X.2007.11782441

[17] Alvarez, J., Mar, J., Varela, E., Garea, M. and Martinez, L. (2012) Cost Analysis of Real-Time Polymerase Chain Reaction Microbiological Diagnosis in Patients with Septic Shock. Anaesthesia and Intensive Care, 40, 958-963. https://doi.org/10.1177/0310057X1204000606

[18] Softić, I., Tahirović, H., Di Ciommo, V. and Auriti, C. (2017) Bacterial Sepsis in Neonates: Single Centre Study in a Neonatal Intensive Care Unit in Bosnia and Herzegovina. Acta Medica Academica, 46, 7-15. https://doi.org/10.5644/ama2006-124.181

[19] Markota, A. and Sinkovič, A. (2018) Mortality, Intensive Care Treatment, and Cost Evaluation: Role of a Polymerase Chain Reaction Assay in Patients with Sepsis. Journal of International Medical Research, 46, 79-88. https://doi.org/10.1177/0300060517719768

[20] Reyna, J., Ortiz, J. and Morales, I. (2010) Use of the LightCycler SeptiFast Test for Rapid Etiologic Diagnosis of Nosocomial Infection in Gynecological Sepsis. Gynecologic and Obstetric Investigation, 70, 215-216. https://doi.org/10.1159/000318868

[21] Maldonado, S.K., Reyna, F.J., Ortiz, I.F.J., Valenzuela, M.E. and Limón, R.A.E. (2011) Uso de la prueba lightCycler ${ }^{\circledast}$ Septifast en un recién nacido y un lactante para el diagnóstico etiológico rápido de sepsis nosocomial por Candida parapsilosis. Revista de Enfermedades Infecciosas en Pediatría, 25, 75-78.

[22] Meisner, M. (2005) Biomarkers of Sepsis: Clinically Useful? Current Opinion in Critical Care, 11, 473-480. https://doi.org/10.1097/01.ccx.0000176694.92883.ce

[23] Chauhan, N., Tiwari, S. and Jain, U. (2017) Potential Biomarkers for Effective Screening of Neonatal Sepsis Infections: An Overview. Microbial Pathogenesis, 107, 234-242. https://doi.org/10.1016/j.micpath.2017.03.042

[24] Sharma, D., Farahbakhsh, N., Shastri, S. and Sharma, P. (2018) Biomarkers for Diagnosis of Neonatal Sepsis: A Literature Review. The Journal of Maternal-Fetal \& Neonatal Medicine, 31, 1646-1659. https://doi.org/10.1080/14767058.2017.1322060

[25] Westh, H., Lisby, G., Breysse, F., Boddinghaus, B., Chomarat, M., Gant, V., et al. (2009) Multiplex Real-Time PCR and Blood Culture for Identification of Bloodstream Pathogens in Patients with Suspected Sepsis. Clinical Microbiology and Infection, 15, 544-551. https://doi.org/10.1111/j.1469-0691.2009.02736.x 